\title{
RAISING CLIMATE RESILIENCE IN BUILDINGS ON THE WESTERN MEDITERRANEAN COAST-MERGING PASSIVE AND ACTIVE NATURAL VENTILATIVE COOLING TECHNIQUES
}

\author{
DOI: 10.18485/arh_pt.2020.7.ch23
}

\author{
_ Nikola Pesic \\ PhD student, Barcelona School of Architecture (ETSAB); Avinguda \\ Diagonal, 649; 08028 Barcelona, Spain; nikola.pesic@upc.edu
}

\author{
_ Adrian Muros Alcojor \\ Professor, Barcelona School of Architecture (ETSAB), Technology department (TA); \\ Avinguda Diagonal, 649; 08028 Barcelona, Spain; adrian.muros@upc.edu \\ _ Jaime Roset Calzada \\ Professor, Barcelona School of Architecture (ETSAB), Physics department (FIS); \\ Avinguda Diagonal, 649; 08028 Barcelona, Spain; jaime.roset@upc.edu
}

\begin{abstract}
This paper presents the considered capabilities to improve space cooling energy efficiency in the Mediterranean climate ambience by merging and optimizing selected natural ventilative techniques. The first part of this analysis defines a set of control strategies based on specific configurations of cross ventilation and fan-assisted advanced natural ventilation. The objective is to take advantage of principally lower nocturnal temperature ranges, due to being less affected by the current climate change effects, and to reflect such a potential in the reduction of day-time cooling energy loads. The second part of the study examines the integration of defined control strategies into a climate responsive building form of a mid-rise office-type building positioned in three different geographical locations along the Catalonian coastline-the cities of Barcelona, Terrassa and Tarragona. In order to provide a comparative overview of energy efficiency for each applied control strategy, the building model is exposed parallel to present and future estimated climate change effects in the building performance simulation environment while the general control and adjustments of established indoor airflow patterns are done by computational fluid dynamics analyses. The generated output demonstrates that under the present-day climate conditions the achieved reduction of cooling energy demands is in the range between $53 \%$ and $65 \%$. Looking further at the horizon of 2050 , it accounts between $58 \%$ and $62 \%$, while in 2080 the overall cut in cooling energy demands is between $54 \%$ and $57 \%$. The comparative overview indicates that despite the rise of day-time temperatures due to climate change effects, the proposed bioclimatic responsive building form based on lower nocturnal temperatures displays considered capabilities in cutting cooling energy demands in the Mediterranean climate ambiance in mid- and long-term periods in the future.
\end{abstract}

KEYWORDS _ natural ventilation, passive and active space cooling,

system optimization, climate responsive building, the Mediterranean climate 


\section{INTRODUCTION}

At the level of Catalonia, current average yearly air temperature is $+1.6^{\circ} \mathrm{C}$ higher than the average regional air temperature throughout 20th century, which can be observed as the average decennial increase of $+0.25^{\circ} \mathrm{C}$. In addition, 2018 was the seventh consecutive year with the highest air temperatures from 1950 , reflected as the rise of $+0.83^{\circ} \mathrm{C}$. The same period of recordings (1950-2018) indicates that the current rise of regional day-time air temperatures is higher than the rise of nocturnal temperature ranges, summarized as $+0.31^{\circ} \mathrm{C}$ versus $+0.19^{\circ} \mathrm{C}$ per decade-or the ratio $1.6: 1$. This aspect forms the research hypothesis that regional nocturnal natural ventilation (NV) cooling capacities in buildings will be more efficient in the future, proportionally to these ranges.

\section{BUILDING MODEL DESIGN PROCEDURE}

\section{Control strategies setup}

This study considers that advanced natural ventilation (ANV) centre-in, edge-out (C-E) form, defined by Lomas (2007), is aimed for the day-time operation and that is fan-supported, that is to say, its airflow is forced by the negative pressure difference effect produced by exhaust fans. On the other side, the use of cross ventilation (CV) is aimed for the night-purge or the night flushing process of building's high-thermal mass.

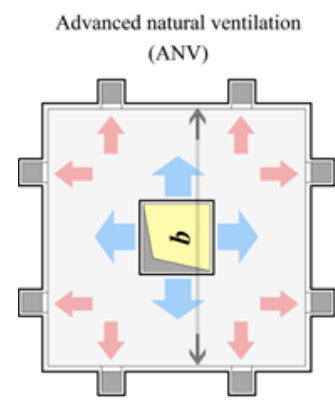

deep-plan

(a)

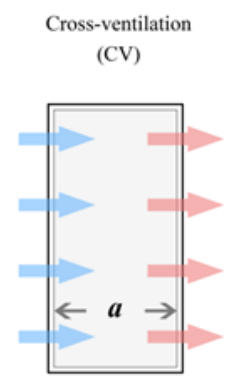

narrow-plan

(b)

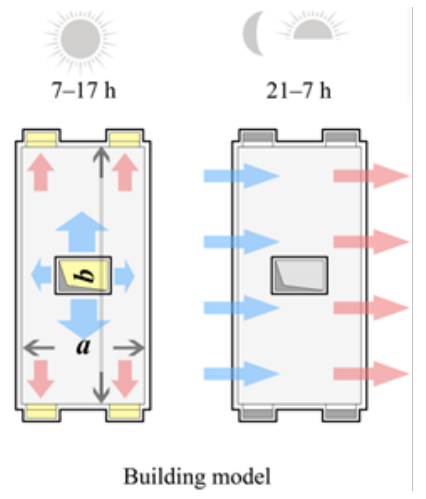

(c)

(d)

Summarizing the chosen ventilative strategies for this analysis, fan-assisted ANV C-E system runs during day-time $7-17 \mathrm{~h}$ as the hybrid or mixed-mode approach, with the support of air-conditioning (AC) equipment and is considered as a closed system, more resilient to climate effects-the airflow pattern is based on the air-shaft-to-chimney direction (Figure 1a). On the other side, CV operates as a nocturnal and completely passive cooling system $21-7 \mathrm{~h}$, considered as an open system with window-to-window airflow direction-directly exposed to weather conditions (Figure 1b). These two ventilative principles are merged into a single building model, regarded as a climate responsive building form with applied multilevel NV cooling approach (Figures 1c,d). 
_ Table 1: Space cooling control strategies (CS): overview for a $24 \mathrm{~h}$ operation period.

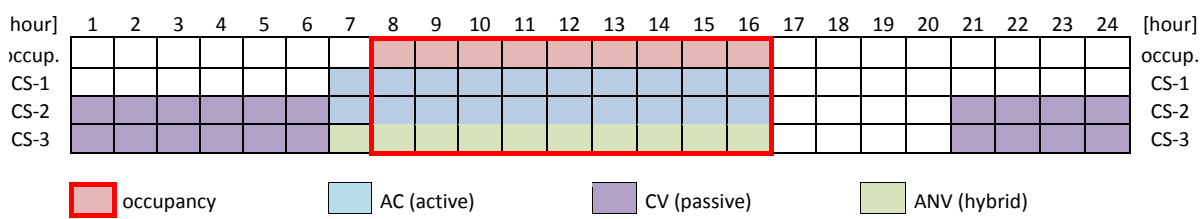

For the comparative analysis of achieved levels of energy efficiency, the same building form is programmed with three different space cooling control strategies (CS-1, CS-2 and CS-3) (Table 1). The complete cooling system is programmed as a $20 \mathrm{~h}$ continuous ventilation period, $21-17 \mathrm{~h}$ (next day), including Sunday night function $21-7 \mathrm{~h}$. The occupancy schedule is defined $8-17 \mathrm{~h}$, while all mechanical ventilative systems operate $7-17 \mathrm{~h}$.

_ Control strategy "1" (CS-1)-AC (air-conditioning): fully equipped AC system planned for reference cooling energy loads, operates $7-17 \mathrm{~h}$, i.e., starting the cooling process one hour before the occupancy established schedule $8-17 \mathrm{~h}$;

_ Control strategy "2" (CS-2)-AC + CV (air-conditioning and cross ventilation): AC system operates $7-17 \mathrm{~h}$, while $\mathrm{CV}$ covers the night-time and the early morning period $21-7 \mathrm{~h}$ (next day) and is aimed for the nocturnal and early morning flushing process of building's high-thermal mass;

_ Control strategy " 3 " (CS-3) - CV + ANV (cross ventilation and advanced natural ventilation): 7-17 h ANV and AC are programmed as a hybrid or mixed-mode ventilation type, with an applied change-over function-both systems are operating in same space, different times. On the other side, CV keeps running $21-7 \mathrm{~h}$, as the night-time passive cooling operation.

\section{Layout and orientation}

The defined building model for DesignBuilder's simulations represents an isolated typical floor of a mid-rise office-type building.

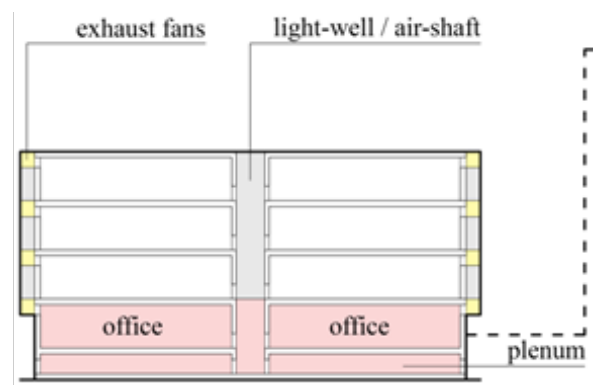

(a)

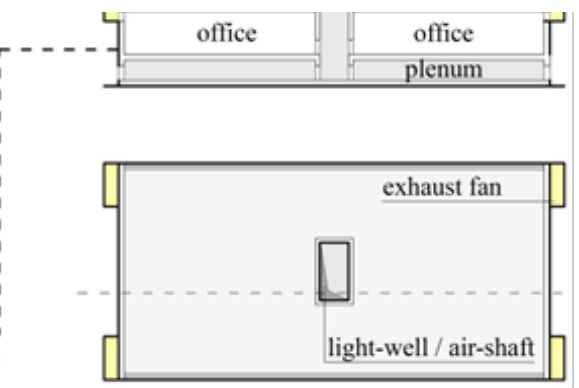

(b)

_ Figure 2: Model of a mid-rise office-type building-the design concept: (a) building cross-section; (b) isolated typical floor with the ground floor plenum: floor plan (bellow), cross-sections (above) (source: by author, 2020).

The rectangular building footprint represents a common office narrow-plan shape, $30.0 \mathrm{~m} \times 15.0 \mathrm{~m}$ (Figure 2). The floor design is considered as an open-plan or office landscape, that is to say, without partitions. 


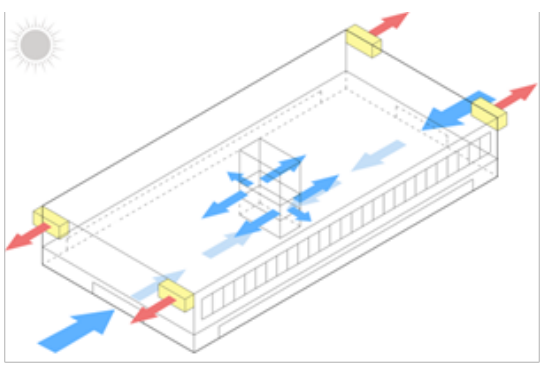

(a)

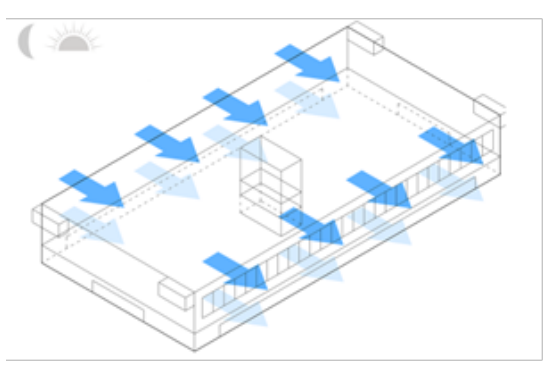

(b)

_ Figure 3: Axonometric view of building model design based on natural ventilation (NV) airflow patterns: (a) day-time fan-assisted advanced natural ventilation (ANV) operation 7-17 h; (b) night-time and early morning cross ventilation (CV) operation $21-7 \mathrm{~h}$.

A light-well or an air-shaft $4.0 \mathrm{~m} \times 2.0 \mathrm{~m}$ is positioned in the centre with a primary function to deliver vertically the fresh air from the ground floor plenum, as a part of an established ANV airflow pattern (Figures 2 and $3 a$ ). The floor-to-ceiling height is $\mathrm{h}=3.0 \mathrm{~m}$.

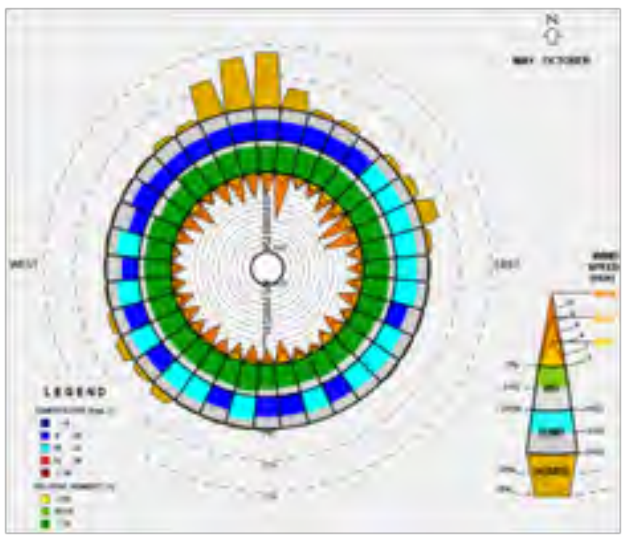

(a)

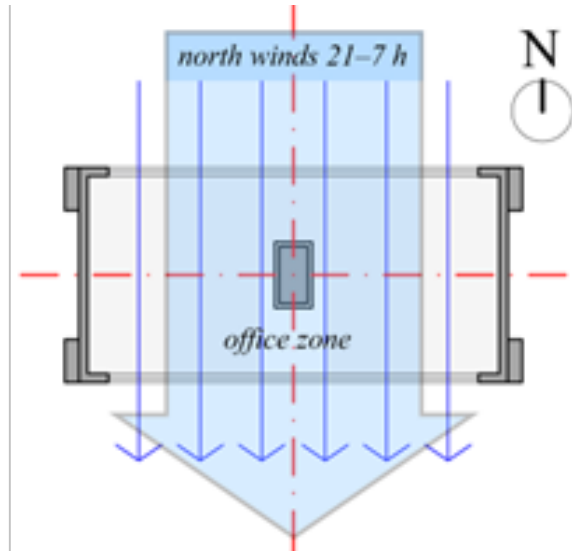

(b)

- Figure 4: Considered wind aspects in building design: (a) wind wheel-average wind parameters in Barcelona, for the selected period May-October, 21-7 h; data image generated by ClimateConsultant software; (b) building model orientation perpendicular to dominant night-time north winds (source: by author, 2020).

From weather data are filtered parameters for local winds for the specific period May-October, 21-7 $\mathrm{h}$ (Figure 4a). The building is oriented perpendicularly to dominant regional north winds in order to fully exploit the potential of wind-generated $\mathrm{CV}$ for the night-time and early morning flushing process of building's high-thermal mass. The central light-well is oriented perpendicularly to the longer east-west axis in order that a transversal direction of $\mathrm{CV}$ is less obstructed (Figures $3 \mathrm{~b}$ and $4 \mathrm{~b}$ ). The opposite north and south facades are with provided continuous ribbon or linear windows with the aim to maximize the efficiency of CV. The building envelope is insulated according to Passivhaus recommendations for the warm temperate climate zone: the maximum considered value for the heat transfer coefficient $(\mathrm{U})$ for the building envelope is $0.3 \mathrm{~W} /\left(\mathrm{m}^{2} \mathrm{~K}\right)$ and for the vertical glazing is $1.05 \mathrm{~W} /$ $\left(\mathrm{m}^{2} \mathrm{~K}\right)$. All building zones are with a constant $24 \mathrm{~h}$ infiltration rate of $0.3 \mathrm{ac} / \mathrm{h}$. In order to minimize the 
solar radiation, window panes are additionally improved with an exterior layer of coated glass with the high solar reflectance level. Along the south facade are applied exterior louvres, while in the interior are mounted high-reflective window blinds. For the building's high-thermal mass is considered concrete with volumetric mass density $(\rho)=2.000 \mathrm{~kg} / \mathrm{m}^{3}$, as fully exposed material positioned in the key-locations along the natural ventilative airflow lines: in the plenum (the ceiling and the ground floor slab, the interior layer of façade walls) and in the office space (the ceiling slab).

Heating, ventilation, and air conditioning (HVAC) design

The heating, ventilation, and air conditioning (HVAC) system is designed in DesignBuilder software with activated functions: calculated natural ventilation and detailed HVAC.

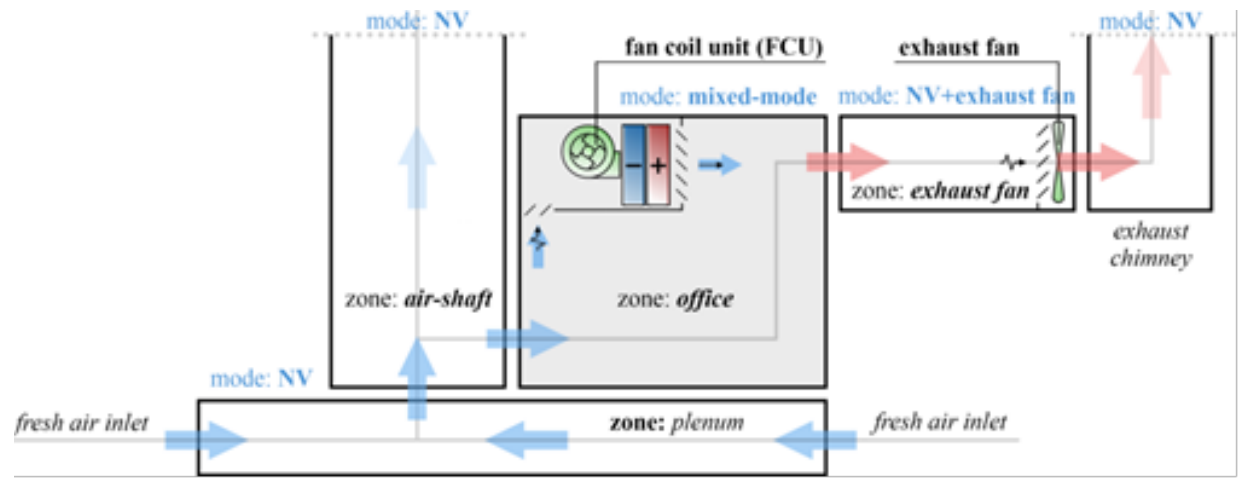

_ Figure 5: Schematic presentation of DesignBuilder's detailed HVAC developed system: advanced natural ventilation (ANV) airflow direction and interconnected building zones (source: by author, 2020).

The office zone is equipped with the fan coil unit (FCU) system supplied by air cooled chillers (Figure 5). The chillers' coefficient of performance (CoP) is set at 3.5 and the mechanical ventilation delivers constantly $7-17 \mathrm{~h}$ the minimum rate of fresh air at $10 \mathrm{l} /$ person. AC cooling temperature is set at $+24.0^{\circ} \mathrm{C}$, while NV cooling temperature that controls ANV day-time operation and CV night purge process is set at $+20.5^{\circ} \mathrm{C}$. The control of minimum outside temperatures is set at $+14.0^{\circ} \mathrm{C}$, below which one all windows and vents are closed, as the prevention against an overcooling effect during night CV operation. Each of four exhaust fans is defined with the flow rate of $0.3 \mathrm{~m}^{3} / \mathrm{s}$, the power supply of $45 \mathrm{~W}$, the efficiency is 0.75 and the fan pressure is $125 \mathrm{~Pa}$. The office zone equipment is considered with a high-level of energy efficiency-heat gains are set at $10 \mathrm{~W} / \mathrm{m}^{2}$.

\section{COMPUTATIONAL FLUID DYNAMICS (CFD) ANALYSES-BARCELONA, PRESENT-TIME}

CFD analyses visualise the airflow patterns generated by natural ventilative means and are presented through selected section planes (Table 2 and Figure 6).

_ Table 2: Structure of presented section planes for Computational Fluid Dynamics (CFD) analyses.

\begin{tabular}{|c|c|c|c|c|c|}
\hline $\begin{array}{l}\text { Office space } \\
\text { floor plan }\end{array}$ & & $\begin{array}{l}\text { Office space and pl } \\
\text { cross-sections }\end{array}$ & & $\begin{array}{l}\text { Plenum } \\
\text { floor plan }\end{array}$ & \\
\hline $\begin{array}{l}\text { 1.a ANV operation } \\
\text { 1.b CV operation }\end{array}$ & $\begin{array}{l}\text { (Figure 7a) } \\
\text { (Figure 7b) }\end{array}$ & $\begin{array}{l}\text { 2.a ANV operation } \\
\text { 2.b CV operation } \\
\text { 2.c ANV operation }\end{array}$ & $\begin{array}{l}\text { (Figure 8a) } \\
\text { (Figure 8b) } \\
\text { (Figure 9) }\end{array}$ & $\begin{array}{l}\text { 3.a ANV operation } \\
\text { 3.b CV operation }\end{array}$ & $\begin{array}{l}\text { (Figure 10a) } \\
\text { (Figure 10b) }\end{array}$ \\
\hline
\end{tabular}




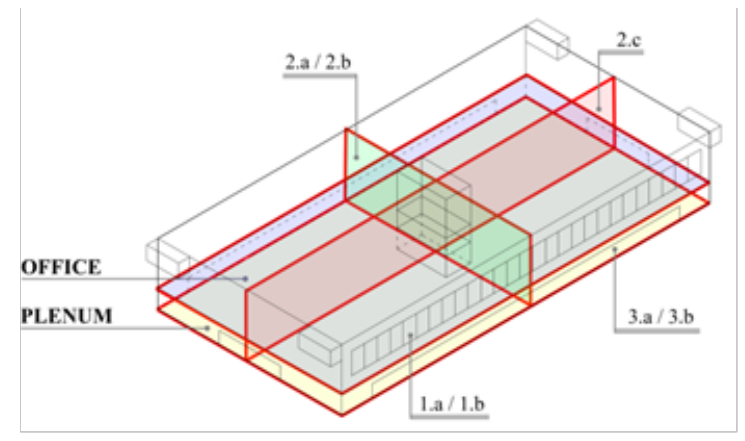

_ Figure 6: Schematic presentation of building model with marked plans and cross-sections for visualisation of computational fluid dynamics (CDF) analyses (source: by author, 2020).
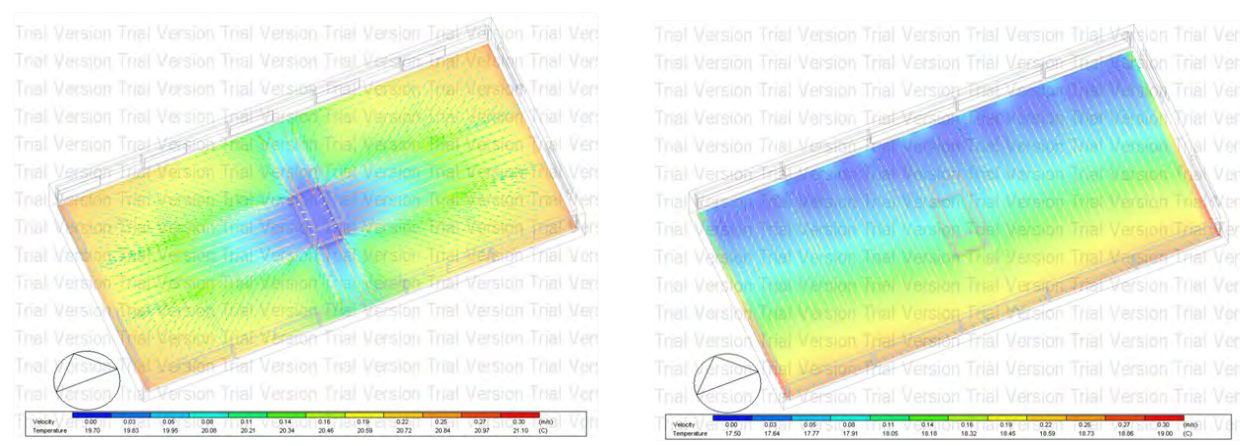

_ Figure 7a (left): Computational fluid dynamics (CFD) analyses of applied natural ventilative space cooling techniques in summer period; axonometric view: advanced natural ventilation (ANV) operation, 12th June at $14 \mathrm{~h}$ (image dataset generated by DesignBuilder software)

_ Figure 7b (right): Computational fluid dynamics (CFD) analyses of applied natural ventilative space cooling techniques in summer period; axonometric view: cross ventilation (CV) operation, 8th July at $5 \mathrm{~h}$ (image dataset generated by DesignBuilder software).
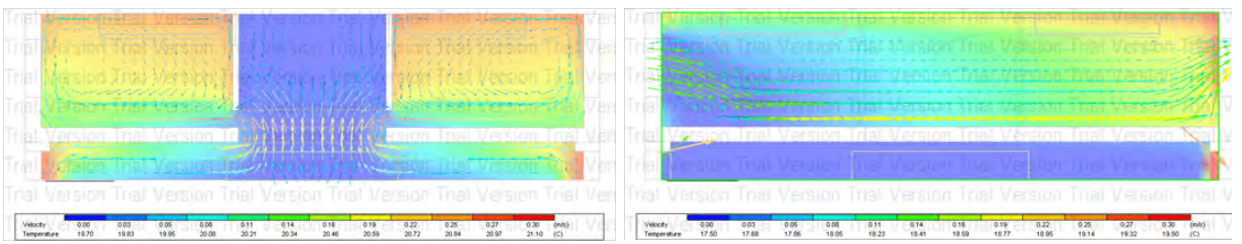

_ Figure 8a (left): Computational fluid dynamics (CFD) analyses of applied natural ventilative space cooling techniques in summer period; cross-section: advanced natural ventilation (ANV) operation, 12th June at $14 \mathrm{~h}$ (image dataset generated by DesignBuilder software).

_ Figure 8b (right): Computational fluid dynamics (CFD) analyses of applied natural ventilative space cooling techniques in summer period; cross-section: cross ventilation (CV) operation, 8th July at $5 \mathrm{~h}$ (image dataset generated by DesignBuilder software). 


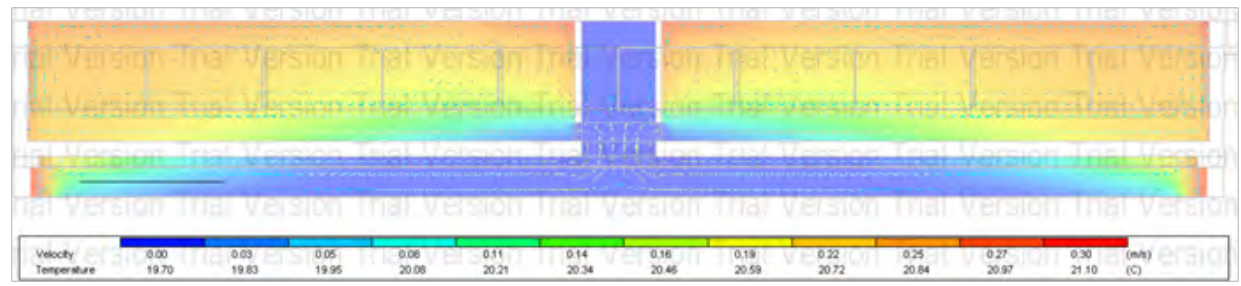

_ Figure 9: Computational fluid dynamics (CFD) analysis of applied natural ventilative space cooling technique; longitudinal cross-section; advanced natural ventilation (ANV) operation, summer period; 12th June at $15 \mathrm{~h}$ (source: image dataset generated by DesignBuilder software).

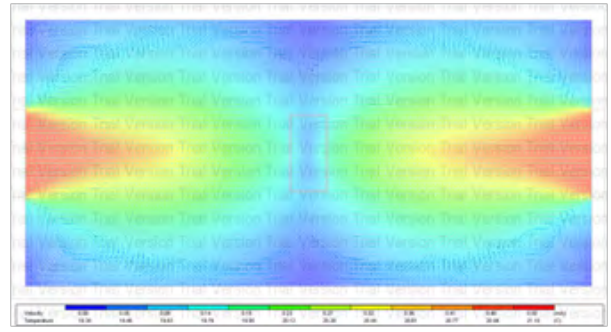

(a)

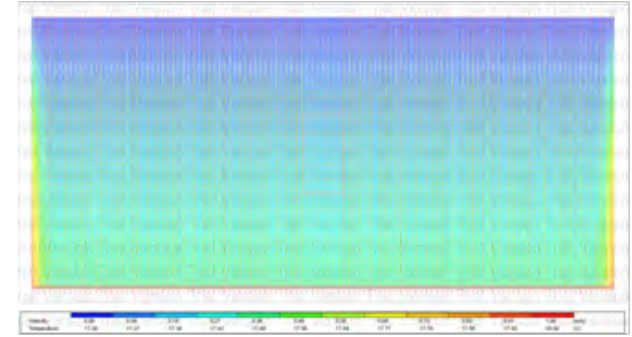

(b)

_ Figure 10: Computational fluid dynamics (CFD) analyses of applied natural ventilative space cooling techniques in summer period; plenum floor plan: (a) advanced natural ventilation (ANV) operation, 12th June at 14 h; (b) cross ventilation (CV) operation, 8th July at 5 h (image dataset generated by DesignBuilder software).

\section{INITIAL RUNNING OF REFERENCE AIR-CONDITIONING SYSTEM}

In the first step, the building model with sized initial AC equipment for the present-day weather conditions is exposed parallel to projected climate change scenarios for 2050 and 2080 . The Climate Change World Weather File Generator (CCWorldWeatherGen) software is aimed for output of weather data that are modified according to the applied scenarios for $\mathrm{CC}$ effects for a specific geographical location. CCWorldWeatherGen is developed on a platform of Intergovernmental Panel on Climate Change (IPCC) Third Assessment Report model summary data of the HadCM3 A2 experiment ensemble which is available from the IPCC Data Distribution Centre (IPCC DDC). Its main function is that uses present-day EPW weather data files in order to modify reference parameters according to applied scenario of climate change effects, in this case, for the horizons of 2050 and 2080.

_ Table 3: Building model exposed to weather conditions in Barcelona, Terrassa and Tarragona; output for 2009, 2050 and 2080: HVAC start-up time, chiller sizing, cooling loads and thermal comfort deviations (source: output generated by Excel software, image edited by author, 2020).

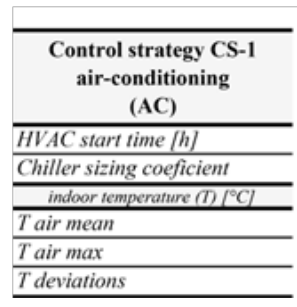

\begin{tabular}{|c|c|c|}
\hline $\mathrm{A}$ & B & C \\
\hline \multicolumn{3}{|c|}{ Barcelona } \\
\hline & \multicolumn{2}{|c|}{ overheating } \\
\hline 2009 & 2050 & 2080 \\
\hline $07: 00$ & $07: 00$ & $07: 00$ \\
\hline 1.0 & 1.0 & 1.0 \\
\hline 25.1 & 27.0 & 28.4 \\
\hline 27.6 & 30.9 & 33.3 \\
\hline 1.1 & 2.1 & 2.6 \\
\hline
\end{tabular}

\begin{tabular}{|c|c|c|}
\hline D & $\mathrm{E}$ & $\mathrm{F}$ \\
\hline \multicolumn{3}{|c|}{ Terrassa } \\
\hline & \multicolumn{2}{|c|}{ overheating } \\
\hline 2009 & 2050 & 2080 \\
\hline $07: 00$ & 07:00 & $07: 00$ \\
\hline 1.0 & 1.0 & 1.0 \\
\hline 25.6 & 27.8 & 29.2 \\
\hline 27.9 & 31.4 & 34.4 \\
\hline 1.3 & 2.2 & 2.5 \\
\hline
\end{tabular}

\begin{tabular}{|c|c|c|}
\hline $\mathrm{G}$ & $\mathrm{H}$ & I \\
\hline \multicolumn{3}{|c|}{ Tarragona } \\
\hline & \multicolumn{2}{|c|}{ overheating } \\
\hline 2009 & 2050 & 2080 \\
\hline $07: 00$ & $07: 00$ & $07: 00$ \\
\hline 1.0 & 1.0 & 1.0 \\
\hline 26.2 & 28.3 & 29.8 \\
\hline 28.8 & 32.3 & 34.3 \\
\hline 1.5 & 2.4 & 2.7 \\
\hline
\end{tabular}




\begin{tabular}{l}
\hline Tradiant mean \\
$\frac{T \text { radiant max }}{T \text { deviations }}$ \\
\hline$\frac{\text { adaptive thermal comfort }}{\text { model } 90 \%: \text { deviations }[\mathrm{h}]}$ \\
\hline model $80 \%:$ deviations $[\mathrm{h}]$ \\
\hline Cooling loads $\left[\mathrm{Wh} / \mathrm{m}^{2}\right]$ \\
\hline Energy efficiency $[\%]$ \\
\hline l. May-31. October: $4,392 \mathrm{~h})$
\end{tabular}

\begin{tabular}{|r|r|r|}
\hline 24.8 & 26.9 & 28.2 \\
\hline 27.3 & 30.7 & 32.7 \\
\hline 1.2 & 2.1 & 2.6 \\
\hline
\end{tabular}

\begin{tabular}{|r|r|r|}
\hline 25.4 & 27.7 & 29.1 \\
\hline 27.6 & 31.2 & 33.1 \\
\hline 1.3 & 2.1 & 2.5 \\
\hline
\end{tabular}

\begin{tabular}{|r|r|r|}
\hline 26.0 & 28.2 & 29.6 \\
\hline 28.8 & 32.0 & 34.0 \\
\hline 1.5 & 2.3 & 2.7 \\
\hline
\end{tabular}

\begin{tabular}{|r|r|r|}
\hline 0.0 & 352.0 & 636.0 \\
\hline 0.0 & 103.0 & 348.0 \\
\hline
\end{tabular}

\begin{tabular}{|l|l|l|}
\hline 0.0 & 646.0 & 846.0 \\
\hline 0.0 & 239.0 & 605.0 \\
\hline
\end{tabular}

\begin{tabular}{|r|r|r|}
\hline 59.9 & 661.0 & 850.0 \\
\hline 0.0 & 338.0 & 636.0 \\
\hline
\end{tabular}

\begin{tabular}{|c|c|c|}
\hline 4,729 & 5,509 & 5,729 \\
\hline & \multicolumn{2}{|c|}{ overheating } \\
\hline
\end{tabular}

\begin{tabular}{|c|c|c|}
\hline 5,063 & 5,486 & 5,610 \\
\hline & \multicolumn{2}{|c|}{ overheating } \\
\hline D & $\mathrm{E}$ & $\mathrm{F}$ \\
\hline
\end{tabular}

\begin{tabular}{|c|c|c|}
\hline 5,945 & 5,726 & 5,839 \\
\hline \multicolumn{3}{|c|}{ overheating } \\
\hline $\mathrm{G}$ & $\mathrm{H}$ & $\mathrm{I}$ \\
\hline
\end{tabular}

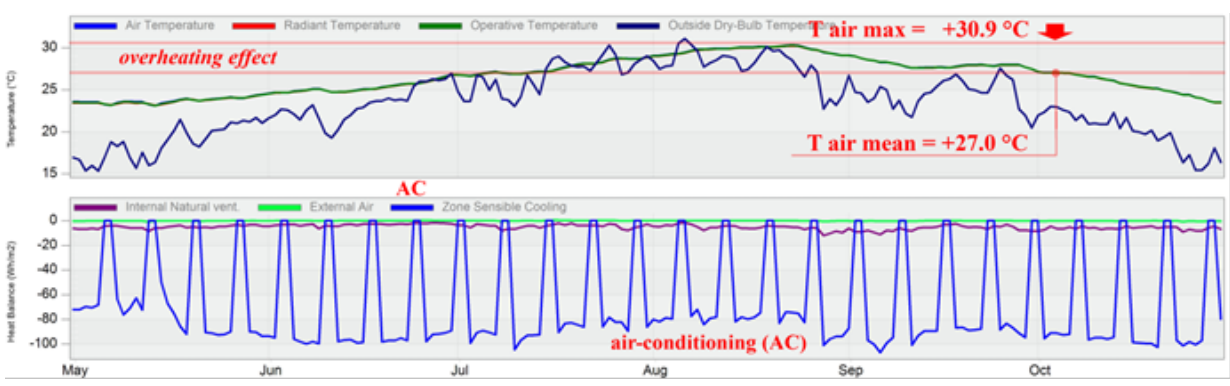

_. Figure 11: Graphical representation of data as temperature and heat balance overview; Barcelona, 2050; overheating effect, control strategy CS-1, office space: air-condition (AC) operation 7-17 h, May-October (source: image dataset generated by DesignBuilder software, post-processed image by author 2020).

All building models show the high level of space overheating effects in 2050 and 2080, which is reflected in high interior air temperatures (Table 3, columns B, C, E-I). These determined effects indicate a general inefficiency of present-day sized $A C$ equipment for this region regarding future climate condition. As an example of this effect, the AC operation in 2050 for the building model positioned in Barcelona is presented in Figure 11. The indoor overheating level is consequently reflected in the high degree of deviations considering the adaptive model of $80 \%$ acceptability limits (ASHRAE Standard 55-2017) applied in this case with the purpose only as references scale for an overheating effect.

\section{OPTIMIZATION OF REFERENCE AIR-CONDITIONING SYSTEM}

Regarding DesignBuilder's modelling environment, using the basic sizing of HVAC equipment and preliminary level of evaluations for the purpose of this research, the HVAC system is not structurally changed to meet the climate conditions in the future, in 2050 and 2080, but it is rather optimized in following aspects:

_ Chiller sizing factor: a series of experiments displayed that sizing HVAC equipment more than $+80 \%$ prove to be energy inefficient, that is to say although the sizing of capacity is raised, however, the construction and the interior of building was still overheated regarding the start-up time of $\mathrm{AC}$ at 07:00 $\mathrm{h}$ and it function up to occupancy schedule start at 08:00 $\mathrm{h}$, that is to say, $1 \mathrm{~h}$ is insufficient time to cool down the building structure and interior elements under future climate conditions.

_ Additional time for HVAC start-up: Optimum start control in modern HVAC design is principally based on an algorithm that is developed to start heating or cooling operations at the latest possible time the purpose of establishing the indoor zone to desired occupied temperature levels immediately before scheduled occupancy. It was taken into consideration that adding maximum $5 \mathrm{~h}$ prove to be an optimum for this climate conditions and according to previously additionally sized chillers. 
Summarizing these two aspects the optimization of existing building model HVAC equipment is guided in two directions: sizing chillers up to 1.8 capacity $(+80 \%)$ while adding the maximum of 5 additional hours for the start-up of $\mathrm{AC}$, regarding the effect of the overheated space, that is to say, from current $07: 00 \mathrm{~h}$ to $02: 00 \mathrm{~h}$, as a maximum considered time.

This design approach is defined in the following procedures: for the present-time weather data time schedule is the same for all AC operations 7:00-17:00 h; for 2050 the considered time of AC cooling schedule is $5: 00-17: 00 \mathrm{~h}$ or $4: 30-17: 00 \mathrm{~h}$ and for the year 2080 , as the climate conditions are with the highest considered temperature ranges in this research, the start time, depending on the geographical location, is in range of 2 to $4 \mathrm{~h}$, that is to say, AC operates 2:00-17:00 h, 2:30-17:00 $\mathrm{h}$ and 4:00-17:00 h, in Tarragona, Terrassa and Barcelona, respectively (Table 4).

_ Table 4: Air-conditioning system optimum start-up and chiller sizing, by each city and by year.

\begin{tabular}{ccccccc}
\hline & \multicolumn{2}{c}{2009} & \multicolumn{2}{c}{2050} & \multicolumn{2}{c}{2080} \\
& $\begin{array}{c}\text { Optimum start-up } \\
{[\mathrm{h}]}\end{array}$ & Chiller sizing & $\begin{array}{c}\text { Optimum start-up } \\
{[\mathrm{h}]}\end{array}$ & Chiller sizing & $\begin{array}{c}\text { Optimum start-up } \\
{[\mathrm{h}]}\end{array}$ & Chiller sizing \\
\hline Barcelona & $07: 00$ & 1.0 & $05: 00$ & 1.2 & $04: 00$ & 1.5 \\
Terrassa & $07: 00$ & 1.0 & $05: 00$ & 1.6 & $02: 30$ & 1.7 \\
Tarragona & $07: 00$ & 1.1 & $04: 30$ & 1.7 & $02: 00$ & 1.7 \\
\hline
\end{tabular}

The building model located in Barcelona in 2050 is displayed as an example of optimization process-a comparative overview is displayed with marked differences between initial and optimized performance of HVAC system (Figure 12).

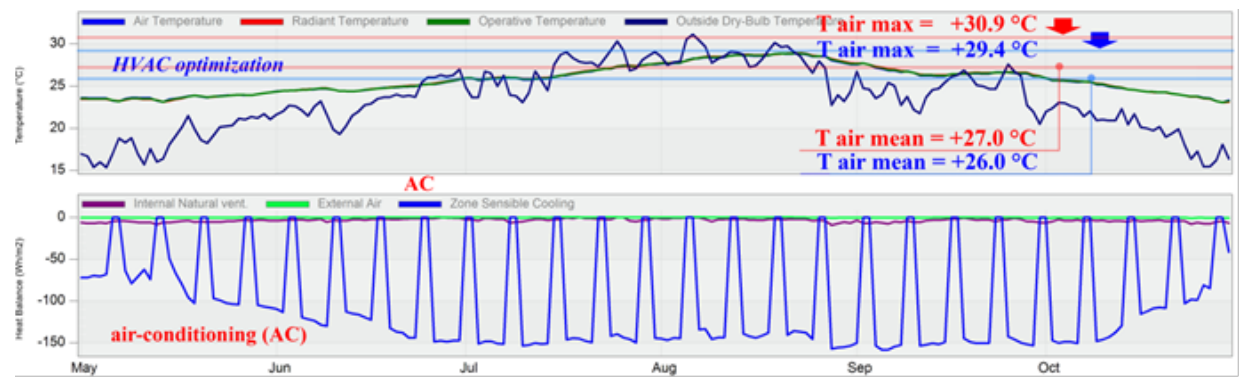

_ Figure 12: Graphical representation of data as temperature and heat balance overview; Barcelona, 2050, optimization; control strategy CS-1, office space: air-condition (AC) operation 7-17 h, May-October (source: image dataset generated by DesignBuilder software, post-processed image by author 2020).

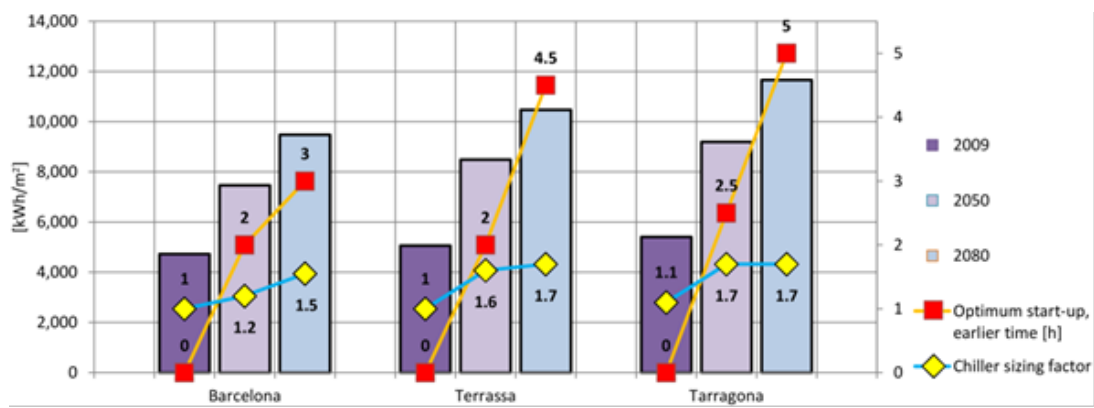

_ Figure 13: Graphical representation of data for optimization of AC systems: additional operational hours and/or additional sizing of equipment (source: output generated by Excel software, by author, 2020). 
The initial series of optimized BPS can be graphically outlined in the Figure 13 , as the correlation between cities, years, total cooling energy demands, chiller sizing factor and optimum start-up, that is to say, the additional time for AC operation in order to cool down the building structure.

\section{FINAL BUILDING PERFORMANCE SIMULATION AND COMPARISON}

The overall output of BPS is displayed as comparative charts (Table 5 and Figure 15). The performance of building model located in Barcelona in 2050 is displayed bellow as an example from a series of nine performed analyses (Figure 14):

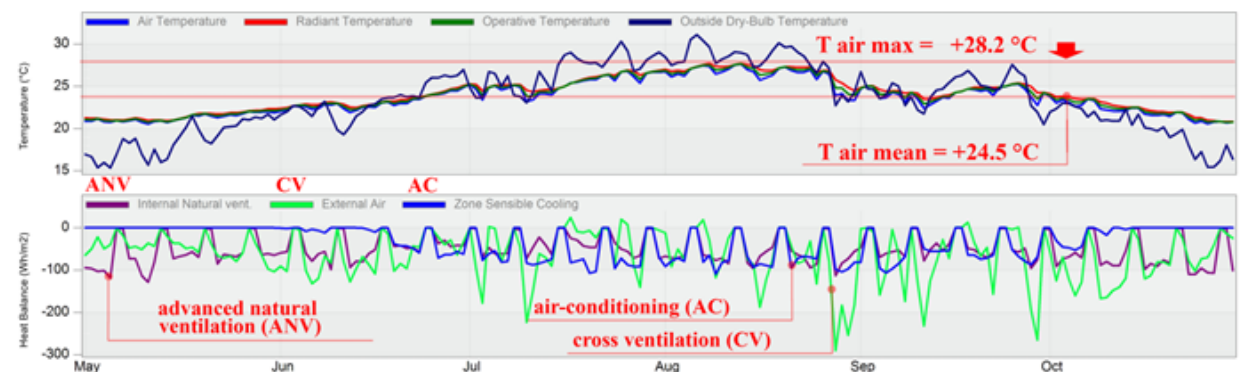

_ Figure 14: Graphical representation of data as temperature and heat balance overview; Barcelona, 2050; control strategy CS-3, office space: air-condition (AC) operation 7-17 h and advanced natural ventilation (ANV) 7-17 h, cross ventilation (CV) 21-7 h, May-October (source: image dataset generated by DesignBuilder)

_ Table 5: Overview of output from building performance simulations (BPS) for cities of Barcelona, Terrassa and Tarragona, for 2009, 2050 and 2080: HVAC start time, chiller sizing coefficient, indoor temperatures, adaptive thermal comfort deviations, cooling loads and energy efficiency (source: output generated by Excel software, edited by author, 2020).

\begin{tabular}{|c|c|c|c|c|c|c|c|c|}
\hline & A & B & $\mathrm{C}$ & D & \multirow[t]{2}{*}{ E } & \multicolumn{3}{|r|}{$\mathrm{H}$} \\
\hline & \multirow{2}{*}{\multicolumn{5}{|c|}{ CS-1 (AC) }} & \multicolumn{3}{|c|}{$\mathrm{CS}-3(\mathrm{CV}+\mathrm{ANV})$} \\
\hline & & & & & & \multicolumn{3}{|c|}{ model $80 \%$ adaptive themal comfort } \\
\hline Barcelona & 2009 & 2050 & 2080 & 2050 & 2080 & 2009 & 2050 & 2080 \\
\hline HVAC start time [h] & $07: 00$ & $07: 00$ & $07: 00$ & $05: 00$ & $04: 00$ & $07: 00$ & $07: 00$ & $07: 00$ \\
\hline Chiller sizing coeficient & 1.0 & 1.0 & 1.0 & 1.2 & 1.5 & 1.0 & 1.0 & 1.0 \\
\hline \multicolumn{9}{|l|}{ avg. indoor temperature $(T)\left[{ }^{\circ} \mathrm{C}\right]$} \\
\hline Tair mean & 25.1 & 27.0 & 28.4 & 26.0 & 26.6 & 23.2 & 24.5 & 25.7 \\
\hline Tair max & 27.6 & 30.9 & 33.3 & 29.4 & 30.2 & 25.6 & 28.2 & 30.2 \\
\hline$T$ deviations & 1.1 & 2.1 & 2.6 & 1.6 & 1.7 & 1.2 & 1.8 & 2.2 \\
\hline Tradiant mean & 24.8 & 26.9 & 28.2 & 26.0 & 26.6 & 22.7 & 24.3 & 25.6 \\
\hline Tradiant $\max$ & 27.3 & 30.7 & 32.7 & 29.3 & 30.2 & 25.4 & 28.1 & 30.1 \\
\hline$T$ deviations & 1.2 & 2.1 & 2.6 & 1.7 & 1.8 & 1.3 & 2.0 & 2.4 \\
\hline \multicolumn{9}{|l|}{ adaptive thermal comfort } \\
\hline model 90\%: deviations $[\mathrm{h}]$ & 0.0 & 352.0 & 636.0 & 11.6 & 8.0 & 94.5 & 62.7 & 47.9 \\
\hline model $80 \%:$ deviations $[\mathrm{h}]$ & 0.0 & 103.0 & 348.0 & 0.0 & 0.0 & 1.8 & 1.7 & 4.9 \\
\hline Cooling loads $\left[\mathrm{Wh} / \mathrm{m}^{2}\right]$ & 4,729 & 5,509 & 5,729 & 7,464 & 9,570 & 1,641 & 3,501 & 4,417 \\
\hline Energy efficiency [\%] & & overhe & ting & optimi: & ation & -65.3 & -53.1 & -53.9 \\
\hline \multirow[t]{3}{*}{ (I. May-31. October: $4,392 \mathrm{~h})$} & A & B & $\mathrm{C}$ & $\mathrm{D}$ & $\mathrm{E}$ & $\mathrm{F}$ & G & $\mathrm{H}$ \\
\hline & \multicolumn{5}{|c|}{ CS-1 (AC) } & \multicolumn{3}{|c|}{$\mathrm{CS}-3(\mathrm{CV}+\mathrm{ANV})$} \\
\hline & & \multicolumn{2}{|c|}{ overheating } & \multicolumn{2}{|c|}{ optimization } & \multicolumn{3}{|c|}{ model $80 \%$ adaptive themal comfort } \\
\hline Terrassa & 2009 & 2050 & 2080 & 2050 & 2080 & 2009 & 2050 & 2080 \\
\hline$\overline{H V A C \text { start time }[\mathrm{h}]}$ & $07: 00$ & $07: 00$ & $07: 00$ & $05: 00$ & $02: 30$ & $07: 00$ & $07: 00$ & $07: 00$ \\
\hline Chiller sizing coeficient & 1.0 & 1.0 & 1.0 & 1.6 & 1.7 & 1.0 & 1.0 & 1.0 \\
\hline
\end{tabular}




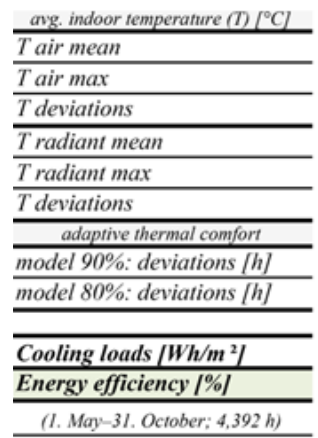

\begin{tabular}{l}
\hline Tarragona \\
\hline HVAC start time $[\mathrm{h}]$ \\
\hline Chiller sizing coeficient \\
\hline avg. indoor temperature $\left.(T){ }^{\circ} \mathrm{C}\right]$ \\
\hline air
\end{tabular}

\begin{tabular}{|r|r|r|}
\hline 25.6 & 27.8 & 29.2 \\
\hline 27.9 & 31.4 & 34.4 \\
\hline 1.3 & 2.2 & 2.5 \\
\hline 25.4 & 27.7 & 29.1 \\
\hline 27.6 & 31.2 & 33.1 \\
\hline 1.3 & 2.1 & 2.5 \\
\hline
\end{tabular}

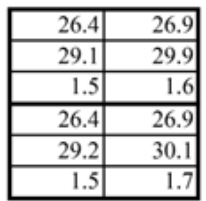

\begin{tabular}{|r|r|r|}
\hline 0.0 & 646.0 & 846.0 \\
\hline 0.0 & 239.0 & 605.0 \\
\hline
\end{tabular}
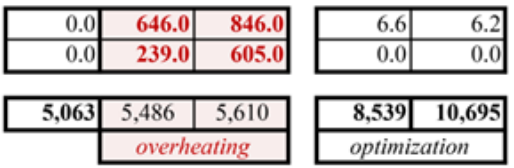

A

B C

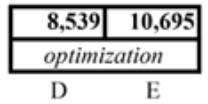

CS-1 (AC)

\begin{tabular}{|c|c|c|}
\multicolumn{1}{c}{} & \multicolumn{2}{c|}{ CS-1 (AC } \\
\cline { 2 - 3 } \multicolumn{1}{c|}{} & \multicolumn{2}{c|}{ overheating } \\
\hline $\mathbf{2 0 0 9}$ & $\mathbf{2 0 5 0}$ & $\mathbf{2 0 8 0}$ \\
\hline $07: 00$ & $07: 00$ & $07: 00$ \\
\hline $\mathbf{1 . 1}$ & 1.0 & 1.0 \\
\hline
\end{tabular}

\begin{tabular}{|c|c|}
\hline \multicolumn{2}{|c|}{ optimization } \\
\hline 2050 & $\mathbf{2 0 8 0}$ \\
\hline $04: 30$ & $\mathbf{0 2 : 0 0}$ \\
\hline 1.7 & 1.7 \\
\hline
\end{tabular}

Tair mean

Tair max

$T$ deviations

Tradiant mean

Tradiant max

$T$ deviations

adaptive thermal comfort

model 90\%: deviations [h]

model 80\%: deviations [h]

Cooling loads $\left[\mathrm{Wh} / \mathrm{m}^{2}\right]$

Energy efficiency [\%]

(I. May-31. October: 4,392 h)

\begin{tabular}{|r|r|r|}
\hline 25.9 & 28.3 & 29.8 \\
\hline 28.4 & 32.3 & 34.3 \\
\hline 1.4 & 2.4 & 2.7 \\
\hline 25.8 & 28.2 & 29.6 \\
\hline 28.2 & 32.0 & 34.0 \\
\hline 1.4 & 2.3 & 2.7 \\
\hline
\end{tabular}

\begin{tabular}{|r|r|r|}
\hline 0.0 & 661.0 & 850.0 \\
\hline 0.0 & 338.0 & 636.0 \\
\hline
\end{tabular}

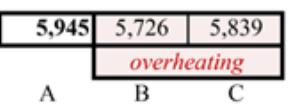

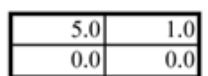

\begin{tabular}{|c|c|}
\hline 9,408 & 11,660 \\
\hline optimization \\
\hline D
\end{tabular}

\begin{tabular}{|r|r|}
\hline 26.7 & 27.1 \\
\hline 29.5 & 30.3 \\
\hline 1.6 & 1.7 \\
\hline 26.8 & 27.2 \\
\hline 29.6 & 30.5 \\
\hline 1.7 & 1.8 \\
\hline
\end{tabular}

\begin{tabular}{|r|r|r|}
\hline 23.2 & 24.6 & 25.8 \\
\hline 25.6 & 28.5 & 30.4 \\
\hline 1.2 & 1.8 & 2.2 \\
\hline 22.9 & 24.5 & 25.8 \\
\hline 25.3 & 28.3 & 30.3 \\
\hline 1.2 & 1.9 & 2.3 \\
\hline
\end{tabular}

\begin{tabular}{|r|r|r|}
\hline 55.6 & 26.0 & 31.9 \\
\hline $\mathbf{1 . 3}$ & $\mathbf{0 . 2}$ & $\mathbf{0 . 1}$ \\
\hline
\end{tabular}

\begin{tabular}{|c|c|c|}
\hline 1,893 & $\mathbf{3 , 4 2 5}$ & $\mathbf{4 , 3 9 6}$ \\
\hline-62.6 & -59.9 & $\mathbf{- 5 8 . 9}$ \\
\hline $\mathrm{F}$ & $\mathrm{G}$ & $\mathrm{H}$
\end{tabular}

CS-3 (CV + ANV)

model $80 \%$ adaptive themal comfort

\begin{tabular}{|c|c|c|}
\hline $\mathbf{2 0 0 9}$ & $\mathbf{2 0 5 0}$ & $\mathbf{2 0 8 0}$ \\
\hline $07: 00$ & $07: 00$ & $07: 00$ \\
\hline 1.0 & 1.0 & 1.0 \\
\hline
\end{tabular}

\begin{tabular}{|c|c|c|}
\hline 23.7 & 25.3 & 26.5 \\
\hline 26.4 & 29.3 & 31.3 \\
\hline 1.3 & 1.9 & 2.4 \\
\hline 23.5 & 25.2 & 26.5 \\
\hline 26.0 & 29.1 & 31.2 \\
\hline 1.4 & 2.1 & 2.5 \\
\hline 57.6 & 24.6 & 81.4 \\
\hline 1.2 & 1.2 & 0.6 \\
\hline
\end{tabular}

\begin{tabular}{|c|c|c|}
\hline 2,705 & 4,123 & 4,990 \\
\hline-54.5 & -56.2 & -57.2 \\
\hline F & G & H
\end{tabular}

_ Figure 15: Graphical representation of data-comparative overview of total energy efficiency [\%] of advanced natural ventilation (ANV) system in Barcelona, Terrassa and Tarragona, for 2009, 2050 and 2080 (source: output generated by Excel software, edited by author, 2020).

The applied exhaust fans have variable activation periods during the ANV airflow support operation. It is assumed that the total energy consumption of four installed exhaust fans during 6 months of cooling period, May-October, is $125 \mathrm{kWh}$ or $305 \mathrm{Wh} / \mathrm{m}^{2}$. However, this parameter in praxis largely depends on a type of installed fans, specific position in the building and variable outdoor conditions impacting the steady airflow of stack-driven ANV-in that way continuously activating and deactivating the fan-support system.

\section{CONCLUSIONS}

The conducted experimental building performance simulations, with three different space cooling control strategies, display that by interrelating cross-ventilation and advanced natural ventilation is possible to reduce cooling energy demands under present-time weather conditions between $53.1 \%$ and $65.3 \%$, in 2050 between $58.9 \%$ and $62.6 \%$, while in 2080 the overall cut in cooling energy demands is estimated to be in the range of $54.5 \%$ and $57.2 \%$. The defined climate responsive building model demonstrates that cross ventilation is functional for the night flushing process of building's high-thermal mass as a complete passive cooling method that relies on a configuration of local variable wind velocities and a lower range of outside nocturnal and early morning temperatures, when the office zone is unoccupied. On the other side, advanced natural ventilation as a more complex hybrid system can be applied as the diurnal cooling approach with a more resilient level of both 
ventilation and cooling operations, regarded through a more stable airflow patterns, maintaining in that manner a controllable level of thermal comfort during an occupancy schedule. However, as it is a fan-supported system, around $1 / 4$ of its energy efficiency is reduced regarding the power consumption of dedicated exhaust fans.

The applied adaptive model of thermal comfort for $80 \%$ occupant acceptability establishes the limits for nocturnal cross ventilation application in case when interior thermal mass could be overcooled, which afterwards, by a radiation effect could reduce interior air temperatures during critical morning hours in these terms, 8-9 h. However these sorts of thermal comfort anomalies could be corrected with a more detailed programing and optimization of cooling operations, or simply by activating heating system in early April and late October, which would be reflected in additional building energy consumption.

Performed analyses demonstrate the compatibility of both applied techniques covering in continuous cycles and without operational collisions the same space but in different parts of the dayviewed as the diurnal and nocturnal NV type, also considered as the open and closed ventilative concept, and as well as the passive and hybrid system approach.

\section{REFERENCES}

_ ANSI/ASHRAE. ANSI/ASHRAE Standard 55-2017 : Thermal Environmental Conditions for Human Occupancy. ASHRAE Inc. 2017;

- ASHRAE. Standard 90.1-2016. Energy Standard for Buildings Except Low-Rise Residential Buildings. Am Soc Heating, Refrig Air-Conditioning Eng Inc. 2016;

- Butlletí Anual d'Indicadors Climàtics. Any 2018 [Internet]. Barcelona; 2019. Available from: https:// static-m.meteo.cat/wordpressweb/wp-content/uploads/2019/11/18121230/BAIC-2018.pdf

_ DesignBuilder Software Ltd. DesignBuilder [Internet]. Stroud, Gloucs, UK: DesignBuilder Software Ltd; 2019. Available from: https://www.designbuilder.co.uk/download/software/release-software

- Hadley Centre Coupled, Version 3 (HadCM3). Hadley Centre for Climate Prediction and Research; 2001.

- Jentsch MF, Bahaj AS, James PAB. Climate change world weather file generator (CCWorldWeatherGen) [Internet]. Sustainable Energy Research Group. Southampton, UK: Sustainable Energy Research Group : The University of Southampton; 2013. Available from: http://www.energy.soton.ac.uk/ccworldweathergen/

- La Agencia Estatal de Meteorología (AEMET). Regionalization AR4-IPCC. Evolution graphics. Regionalización estadística análogos. España peninsular [Internet]. 2020 [cited 2020 Mar 1]. Available from: http:// www.aemet.es/en/serviciosclimaticos/cambio_climat/result_graficos?opc $4=0 \&$ w $=0 \& o p c 1=E s p a n \& o p-$ c2 $=$ Tx\&opc3=Anual\&opc6 $=1$ \&img $=1$

- Lomas KJ. Architectural design of an advanced naturally ventilated building form. Energy Build. 2007;

- Milne M, Benson A, Bhattacharya Y. Climate Consultant [Internet]. UCLA. Los Angeles, USA: UCLA;

2019. Available from: http://www.energy-design-tools.aud.ucla.edu/climate-consultant/request-climate-consultant.php

- Passive House Institute. Criteria for the Passive House, EnerPHit and PHI Low Energy Building Standard. Passiv House Inst. 2016;

- Passive House Institute. Passive House Planning Package (PHPP). passivehouse.com. 2015.

- Pesic N, Calzada JR, Alcojor AM. Assessment of advanced natural ventilation space cooling potential across Southern European coastal region. Sustain. 2018;10(9).

- Pesic N, Calzada JR, Alcojor AM. Natural ventilation potential of the Mediterranean coastal region of Catalonia. Energy Build. 2018;169.

- Spinoni J, Vogt J V., Barbosa P, Dosio A, McCormick N, Bigano A, et al. Changes of heating and cooling degree-days in Europe from 1981 to 2100. Int J Climatol. 2018; 